\title{
O uso do WhatsApp pelo telejornal Tribuna Notícias $1^{a}$ Edição:
}

\author{
Interatividade limitada ou real empoderamento do público?
}

\section{The use of WhatsApp by Tribuna Notícias News Programme}

\section{1st Edition:}

\section{Limited interactivity or real audience empowerment?}

\section{Rafael da Silva Paes Henriques}

Professor adjunto no Departamento de Comunicação Social e professor permanente do Programa de Pósgraduação em Comunicação e Territorialidades da UFES. UFES, Programa de Pós-graduação em Comunicação e Territorialidades, Vitória (ES), Brasil.

\section{Elaine de Lima Castro Garau}

Mestra em Comunicação e Territorialidades pela UFES. UFES, Programa de Pós-graduação em Comunicação e Territorialidades, Vitória (ES), Brasil.

\section{Introdução}

Terça-feira, 29 de março de 2016. Um rapaz de 28 anos morre pouco depois de sair de um supermercado no município de Serra ${ }^{1}$; testemunhas afirmam terem visto o jovem roubando duas peças de picanha do açougue do estabelecimento. Acreditava-se, inicialmente, que ele teria passado mal, talvez um

\footnotetext{
${ }^{1}$ Município mais populoso do Espírito Santo, localizado na região metropolitana de Vitória-ES.
} 


\section{ALCEU}

ISSN: $2175-7402$

ataque cardíaco, ao ser abordado por funcionários depois de o alarme ter disparado. O chefe da equipe de segurança garante que não houve violência na abordagem.

Na redação do telejornal Tribuna Notícias 1a edição $(\mathrm{TN1})^{2}$, os jornalistas começam a receber, por meio de um aplicativo de troca de mensagens no celular, imagens do tumulto em frente ao supermercado. São registros de um homem caído no chão, fotos e vídeos da movimentação de pessoas ao redor; e as primeiras informações, ainda não confirmadas, de como teria sido a morte do "ladrão de carnes". O material é enviado por telespectadores do jornal que presenciaram a morte ou que apenas compartilhavam arquivos de fotos e vídeos que haviam recebido. Muitos se mostram surpresos com o acontecimento tão súbito; alguns chegam a falar em castigo divino. Um deles diz que as imagens são algo que a TV precisava mostrar: um exemplo de que o crime, por menor que seja, não compensa.

Quarta feira, 30 de março de 2016. O delegado Rodrigo Sandi Mori, titular da Divisão de Homicídios e Proteção à Pessoa (DHPP), informa à imprensa o resultado da autópsia no corpo do rapaz: a morte de Jhonatam Barbosa foi comprovadamente provocada por asfixia. Derrubada a versão inicial, dois seguranças são presos. As investigações indicam que eles descobriram o furto, perseguiram o rapaz, conseguiram alcançá-lo em um terreno baldio próximo ao supermercado e depois ficaram sozinhos com a vítima, em um corredor da loja onde não existiam câmeras de monitoramento. Apesar de negarem o crime, ambos são autuados por homicídio qualificado, por motivo fútil, e autorizados a aguardar o julgamento em liberdade ${ }^{3}$.

Na redação do TN1, imagens do caso enviadas por meio do WhatsApp voltam a ser recebidas. Desta vez, enviadas por telespectadores que afirmam estar indignados com a violência extrema da ação dos seguranças que causou a morte de um rapaz tão jovem por um motivo tão banal. De acordo com o que é dito em boa parte das mensagens, as imagens feitas com celulares passam a ser a prova de um crime; o registro de um castigo brutal que o rapaz não merecia. Em alguns textos, a emissora é cobrada a exibir o material, para não deixar que tamanha covardia fique impune.

\footnotetext{
${ }^{2}$ Telejornal exibido de segunda a sábado, atualmente das $11 \mathrm{~h} 45$ às 12h35, na TV Tribuna, emissora afiliada do SBT no Espírito Santo.

3 Outras informações em http://www.tribunaonline.com.br/morte-por-afixia-e-confirmada-e-justica-mandar-soltar-acus-dematar-homem-em-supermercado. Acessado em 21de julho de 2016.
} 


\section{ALCEU}

Nas duas ocasiões, no dia da morte do rapaz e quando o delegado divulgou a reviravolta nas investigações, alguns dos vídeos e fotos recebidos foram aproveitados pela equipe de jornalismo do TN1 e exibidos no telejornal. As imagens e mensagens também auxiliaram na busca por novas informações; algumas traziam detalhes a respeito dos seguranças envolvidos, do rapaz assassinado, e sobre o momento do crime. Elas nortearam novas perguntas feitas pelos produtores à polícia, e indicaram caminhos sobre o que uma parcela dos telespectadores gostaria de ver: 1 ) cobrança para que a polícia trabalhasse com empenho; 2) justiça rápida e punição para os envolvidos; 3) além do histórico pessoal da vítima e a reação da família ao saber do assassinato.

Esse é apenas um exemplo de como o mais conhecido e utilizado aplicativo para troca de mensagens instantâneas da atualidade tem provocado grandes e importantes mudanças na maneira de produzir, transmitir e receber informações, afetando consequentemente as rotinas produtivas relacionadas ao jornalismo e o relacionamento de uma parte dos telespectadores com quem produz profissionalmente informação. Na redação do Tribuna Notícias, o WhatsApp começou a ser usado em abril de 2015, principalmente para troca de mensagens entre membros da equipe e para recebimento de sugestões de pauta enviadas por telespectadores. Ganhou vinheta, status de quadro, e importância já no mês seguinte, em maio do mesmo ano.

O objetivo deste artigo é justamente avaliar como a utilização do aplicativo afetou o relacionamento entre jornalistas e parte do público, e alterou as rotinas produtivas na redação do TN1, nos 18 primeiros meses de implantação, período compreendido entre abril de 2015 e outubro de 2016. Para cumprir com essa tarefa, este estudo de caso utilizou a revisão bibliográfica, a observação participante ${ }^{4}$ e a entrevista semiestruturada. Os dados foram coletados por meio do acesso direto à conta da emissora no aplicativo e também de análises feitas no Easynews, que é o software de automação de redação de telejornalismo mais utilizado no Brasil no momento desta pesquisa.

O telejornal foi analisado durante seis semanas não consecutivas, em meses diferentes, sempre fazendo o acompanhamento semanal de quarta a quarta. A intenção era evitar que um acontecimento de grande interesse jornalístico, geralmente repercutido em vários dias seguidos, dominasse o escopo; ou que um fator capaz de afetar de maneira significativa o ambiente na empresa, como demissões ou mudanças

\footnotetext{
${ }^{4}$ Uma das autoras deste trabalho atuou como editora de texto no TN1 durante boa parte do tempo de realização desta pesquisa, vindo a se desligar da TV Tribuna em 2016.
} 
de horário na grade, interferissem no resultado da pesquisa. As investigações englobaram a rotina dos profissionais da redação, a análise de mensagens recebidas como um todo, a utilização desses conteúdos e o relacionamento com o público, dentro do horário principal relacionado à produção do telejornal específico, ou seja, desde a chegada do primeiro profissional, no início da manhã, até a hora em que o TN1 sai do ar.

Como resultados encontrados, podemos apontar que, apesar de a participação do telespectador ser muito incentivada durante o telejornal, e o clima de intimidade, reforçado a cada fala, o telespectador não tem conhecimento das necessidades do processo jornalístico ou dos interesses da empresa e ainda se mantém distante da seleção do que será efetivamente exibido.

Quem está em casa e assiste às notícias não é identificado como alguém comum, mas é evocado pelos apresentadores como um "amigo do TN". Mas, ainda que o aplicativo permita alguma interação, nossa investigação indicou que uma parcela muito pequena dos telespectadores efetivamente utiliza o WhatsApp para o envio de conteúdos à redação, e, além disso, e mais importante, podemos afirmar que o novo canal de comunicação e de participação da audiência não alterou a linha editorial do produto; isto é, são os jornalistas que continuam decidindo o que é ou o que não é notícia, de acordo com seus próprios valores e interesses profissionais e empresariais. Sendo assim, essa participação é bastante limitada.

Com efeito, podemos indicar que umas das consequências mais visíveis do uso do WhatsApp pela redação do TN1 foi a frustração. Para os profissionais, essa frustração advém da sobrecarga gerada pelo acúmulo de novas funções, que impossibilita a realização, a contento, do trabalho relacionado ao aplicativo. Já muitos dos telespectadores se veem frustrados ao perceberem que suas demandas não recebem a atenção que consideravam adequada. Isso pode ser comprovado pela quantidade de mensagens, recebidas por meio do aplicativo, com teor negativo e com cobranças por mais atenção e retorno, e pelas denúncias formais de telespectadores feitas aos administradores do aplicativo.

\section{Mudanças na rotina produtiva do telejornal}

Até o início da utilização do WhatsApp, a troca de informações entre o telespectador e os jornalistas era feita por meio de ligações telefônicas convencionais, por e-mail e por contato direto com as 
equipes na rua. Raramente algum telespectador procurava diretamente a redação. Antigamente, e ainda hoje, nestes casos, é preciso passar pelo filtro da equipe de segurança da rede. Se os vigilantes analisam que não existe condição perigosa aparente, avisam à equipe. Uma das produtoras, então, costuma dar atenção ao telespectador na portaria mesmo, de maneira educada, mas evitando que ele se prolongue ou atrapalhe o ritmo de trabalho interno. Depois da criação e popularização do Facebook, algumas sugestões e reclamações passaram a ser feitas também pelo perfil do programa na rede social. Depois do WhatsApp, houve uma grande transformação, principalmente no número de chamadas telefônicas convencionais recebidas, como explica uma das produtoras:

Acho que é tão mais prático mandar uma mensagem do que fazer uma ligação (ligação chama, chama até a pessoa atender, a linha fica ocupada... demora para explicar e responder as perguntas) que a participação aumentou muito. $O$ telefone hoje em dia não toca tanto quanto antigamente (PRODUTORA 2, julho 2016)5.

Quando o contato é feito por telefone, fica difícil para os profissionais distinguirem o que é ou não verdadeiro no que é transmitido. Até abril de 2015, quando o aplicativo começou a ser utilizado na redação, a equipe de reportagem saía com as informações na pauta, mas muitas vezes era surpreendida com uma realidade bem distinta da descrita na ligação. Os protestos são um bom exemplo. Antigamente, era preciso acreditar no que o telespectador dizia, e, muitas vezes, eles aumentavam o número de participantes ou a gravidade da manifestação, para forçar a presença do repórter e cinegrafista. Da mesma forma, uma "cratera imensa", "um grande rio de esgoto" ou um "verdadeiro lixão a céu aberto" não passavam de um pequeno buraco na rua não asfaltada, uma fossa transbordando ou algumas sacolas de lixo em local não adequado. Equipes também já se descobriram em situações de extrema insegurança após seguirem para verificação de denúncias falsas. Um dos editores de imagens que trabalha na redação do TN resumiu bem ao responder se o telejornal fica melhor com as participações dos "amigos do TN":

Sim, normalmente nós recebemos informações ou sugestões de pauta por telefone ou e-mail, mas sempre há dificuldade para entender o problema ou visualizar a denúncia. Com o Whatsapp, tudo ficou mais rápido e mais fácil, já que podemos ver por meio das fotos e vídeos a real situação no bairro, hospital, posto de saúde. Só que tem o grande fluxo de vídeos, fotos e áudios recebidos, e isso exige uma nova forma de trabalho para as pessoas que trabalham diretamente com o recebimento de sugestões de pauta (EDITOR DE IMAGENS, 2016).

\footnotetext{
${ }^{5}$ Optamos por não informar o nome de boa parte dos profissionais para preservar a identificação e permitir que ficassem mais à vontade para responder às questões relacionadas à empresa em que trabalham. Gostaríamos também de evitar a indicação do cargo, mas consideramos que esta é importante para a compreensão das declarações e decidimos por informá-la após a autorização dos entrevistados. Os nomes da editora executiva e dos apresentadores estão informados, pois seria possível identificá-los apenas com uma rápida pesquisa com a data e o nome do programa.
} 
Durante o nosso processo de observação in loco na redação do Tribuna Notícias, verificamos que o uso do WhatsApp trouxe consequências e mudanças na forma e no ritmo de atuar de todos os profissionais diretamente envolvidos com o trabalho na redação. Das ruas, repórteres e cinegrafistas podiam receber e enviar essas informações, fotos e vídeos, diminuindo o número de passagens pela empresa, reconfigurando a relação entre território-zona e território-rede, em uma articulação mais flexível de espaços que não são contínuos (HAESBAERT, 2004). Isso tornou mais ágil o processo de produção da notícia, de tal forma que reportagens que anteriormente não seriam produzidas em tempo hábil para exibição na edição acabaram sendo exibidas normalmente.

Havia um grupo no aplicativo, criado para compartilhamento de informações, 24 horas, entre membros da equipe. Verificamos que os profissionais realizavam registros também fora do horário e do local de trabalho. Ao presenciar acontecimentos que julgava serem importantes do ponto de vista jornalístico, a equipe fazia o registro e o cedia para utilização. Imagens feitas por jornalistas de folga, de acidentes ou em situação de grande conflito, por exemplo, sempre rendiam um bom retorno de audiência. Os telefones, com suas câmeras cada vez mais modernas, também são aliados das equipes em locais onde as câmeras profissionais não são permitidas. Depois de registrada, a imagem podia ser enviada imediatamente, por meio do WhatsApp.

Isso significa que, com os smartphones, o funcionário ficou conectado 24 horas por dia. Mesmo que a legislação determine que as empresas respeitem o horário de trabalho definido em contrato, os profissionais são cobrados, e se cobram, por uma postura atenta, até em período de descanso. As consequências aparecem em indivíduos cada vez mais estressados, mais competitivos, com capacidade de percepção alterada por processos de homogeneização, redundância e aceleração; e sem tempo para saúde, lazer ou bem-estar (CRARY, 2014).

A utilização do aplicativo no processo de produção e na relação direta com o telespectador favoreceu a elaboração de uma grande quantidade de pautas, mas acabou por sobrecarregar os profissionais da redação, em especial os produtores e editores de texto. Depois que as mensagens enviadas pelos "amigos do TN" passavam pela primeira triagem, feita pelas duas produtoras, elas eram repassadas à chefia de reportagem, para que as pautas fossem marcadas, ou às editoras de texto, para que fossem trabalhadas e exibidas. Eram as três editoras, com o aval da editora-chefe, que definiam realmente o fato que seria transformado em notícia, de acordo com a relevância, o tempo disponível no telejornal, a 
necessidade de mesclar assuntos e reportagens mais "leves" e mais "pesados", a disponibilidade das ilhas de edição e editores de imagens, e o tempo restante para que o produto jornalístico estivesse pronto para ir ao ar. Algumas vezes, a qualidade do material recebido deixava a desejar tecnicamente, mas era utilizado assim mesmo, em nome da característica de autenticidade, como também apontou Martins (2014).

As duas produtoras também eram responsáveis por outras tarefas, como a produção das reportagens e entrevistas, e pela busca de respostas dos órgãos oficiais e empresas que eram citados no telejornal. Por isso, elas optaram ${ }^{6}$ por monitorar o WhatsApp em esquema de revezamento diário, justamente para dividir o peso da sobrecarga imposta pela nova função. Elas tiveram acesso à média de pouco mais de 300 mensagens por dia, enviadas por telespectadores, no primeiro ano e meio de utilização do aplicativo na redação. Em entrevistas semiestruturadas realizadas durante esta pesquisa, ambas afirmaram acreditar que o trabalho seria feito de maneira mais satisfatória e produtiva se houvesse um profissional para realizar a atividade de maneira exclusiva.

O tempo é um fator crucial. Não é possível ficar todo o tempo lendo e apurando cada mensagem. O ideal seria uma dedicação exclusiva, mas, diante de nossa limitação de pessoal torna-se inviável. Inicialmente, verifico item por item até a madrugada. Dou prioridade ao nosso grupo (TN) para saber se há algum demanda urgente. Depois, olho rapidamente para saber se algum amigo do TN enviou algum factual da hora. Se tiver, já apuro (anoto no arquivo, nome telefone para ficar fácil achar e o que é mais importante na mensagem para facilitar o editor) e demando as equipes e chefias. Se não, continuo avaliando caso a caso (PRODUTORA 1, julho, 2016).

É tudo muito corrido. Nosso tempo é curto e temos que responder todos ao mesmo tempo. Muitas vezes as pessoas que estão enviando a msg não entendem que é uma pessoa só para responder mais de 1.000 mensagens que chegam ao mesmo tempo... aí ficam bemmm nervosas (PRODUTORA 2, julho, 2016).

As mensagens sem relevância jornalística contribuíam muito para a sobrecarga de trabalho enfrentada pelas produtoras. Eram vídeos motivacionais, piadas, fotos, montagens com animais, frases sem sentido ou apenas um cumprimento, e até material pornográfico. Todos os dias, o WhatsApp do TN era adicionado a grupos. Todos esses grupos eram deletados imediatamente, sem que as mensagens fossem lidas. Arquivos de áudio também não eram ouvidos. A responsável por monitorar o aplicativo avisava ao telespectador que o contato precisava ser por escrito e solicitava um novo envio. A maioria não respondia quando isso acontecia. Alguns amigos do TN enviavam mensagens com "Boa tarde, amigo"; "Boa noite"; "Bom dia", diariamente.

\footnotetext{
${ }^{6}$ Assim foi feito durante todo o período de observação para esta pesquisa.
} 
Com tantas mensagens, muitas acabavam ficando sem retorno. E as cobranças também eram feitas por meio do aplicativo, como neste exemplo: "Olá pessoal do tribuna pedi uma ajuda a vocêis pra mim ajuda tira um portão de uma rua que uma invasora invadiu, vocêis ficaro de me ajuda" (sic) (TELESPECTADOR, 2016).

O volume de material recebido no início da utilização do aplicativo na redação foi motivo de comemoração, pois indicava um retorno da solicitação feita pela equipe, além de uma boa fonte de pautas e a possibilidade de maior interação, mas, com o tempo, boa parte delas acabou por ficar sem respostas adequadas. A equipe reduzida não conseguia ler, analisar e dar retorno a todos os "amigos do TN", que, como amigos da vida real, também se ressentem, o que representa um risco. Becker (2016, p. 209) já apontou anteriormente que: “De fato, as tecnologias surgem e são desenvolvidas para atender aos interesses econômicos e políticos dominantes, mas também são apropriadas pela sociedade de formas nem sempre previsíveis".

Foram tantas as denúncias de telespectadores insatisfeitos aos administradores do aplicativo que, em maio de 2016, o WhatsApp do TN foi bloqueado e banido do sistema. A equipe de tecnologia da informação da empresa tentou reverter a situação, mas não conseguiu. Uma nova conta teve que ser providenciada.

É claro que a suspensão temporária do aplicativo provocou uma diminuição na quantidade de mensagens recebidas, notadamente após o período em que ficou fora de serviço, e influenciada também pela mudança no número. O que acabou por reforçar a tendência observada, desde a implantação do WhatsApp, de redução gradual da quantidade de mensagens. Para dar uma ideia dessa queda, no período de elaboração do pré-projeto de pesquisa que deu origem a esta investigação, em abril de 2015, contabilizamos uma média de 390 mensagens diárias. Levantamento do dia 20 de julho de 2016 mostrou um total de 140 mensagens por dia. Uma redução de 64\% no período de um ano e três meses.

Depois da suspensão, foi preciso adotar, mais que um novo número, novas estratégias. A partir desse momento, determinou-se a obrigatoriedade de emitir uma resposta para cada uma das mensagens recebidas, mesmo que fosse apenas um 'obrigada", "bom dia" ou um emoticon sorridente. Só que essa medida aumentou ainda mais a carga de trabalho das produtoras, também porque muitos telespectadores faziam questão de treplicar a resposta, enviando de volta uma nova mensagem como "obrigado" ou mesmo um outro emoticon. 
Verificamos que grande parte das solicitações por WhatsApp já chegava com fotos, vídeos e explicações detalhadas. Quando as mensagens não eram acompanhadas desses recursos, eles eram solicitados pelas produtoras, facilitando descobrir se as pautas eram reais e evitando o desperdício de recursos referentes ao envio da equipe ao local. Ressaltamos que o processo de captação das informações já era facilitado por outros avanços tecnológicos anteriores, mas o WhatsApp mudou de forma extraordinária a facilidade e a velocidade de transmissão desse material.

O exemplo abaixo mostra uma dessas situações. A mãe buscava uma solução para o problema congênito do filho, que apresentava má formação na boca:

Esse aí é o meu filho o Gabriel que estar precisando de um tratamento urgente. E o hospital infantil de vitória não quer mais fazer. Pois falom que não fecharam o diagnóstico. E teria que mandar para o estado do rio Mas não marca a consulta lá. E eu tenho que ficar correndo pra tentar marca. E não consigo $E$ meu filho sofre muito com a boquinha assim. Não consegui se alimentar direito. Sofre de mas. Não quento mas ver o sofrimento dele (TELESPECTADORA, 2016).

A foto da criança sensibilizou a produtora, a reportagem foi feita, e o Gabriel foi encaminhado ao atendimento necessário.

Figura 1 - Imagem atesta e intensifica a informação repassada por telespectadora.

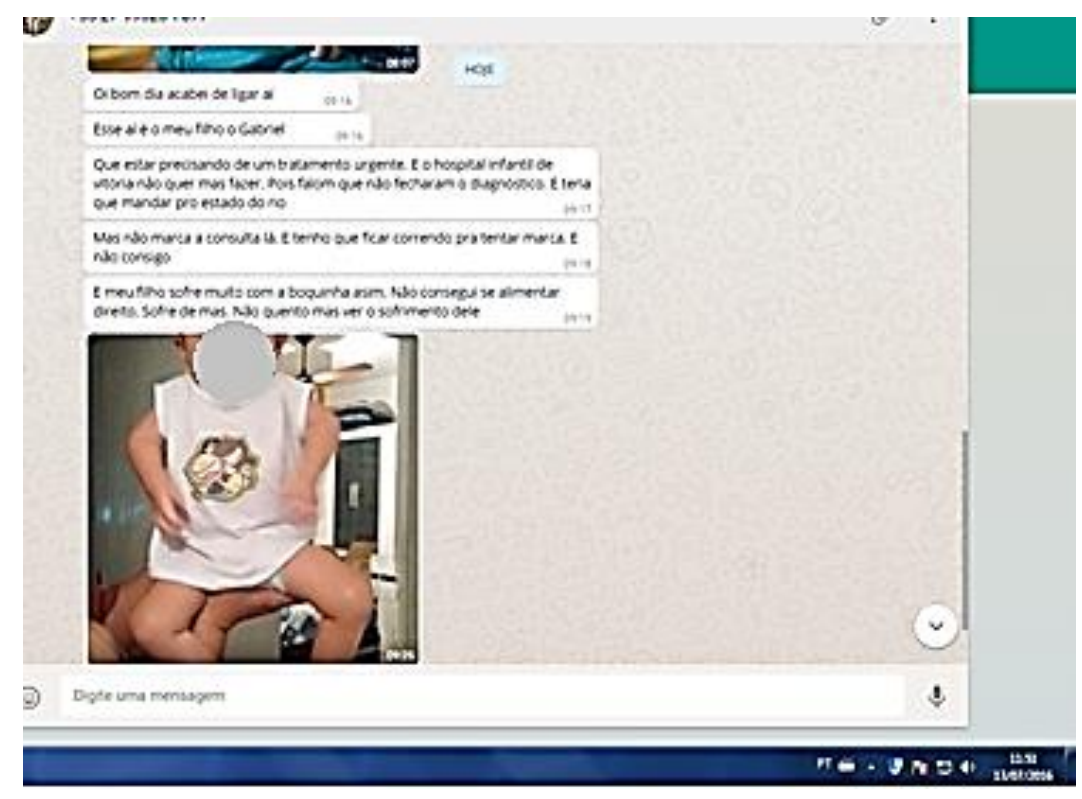

Fonte: captura de tela realizada pelos autores.

Muitas vezes, a informação chegava de fontes confiáveis, mas de maneira não oficial, principalmente quando tinha cunho policial: 
Efetuou um roubo em $\mathrm{BE}^{7}$ juntamente com seu irmão e mais dois indivíduos. Tomando sentido Pinheiros, conseguindo se evadir da guarnição após acompanhamento policial. Que após buscas e diligências foi encontrado a arma e droga com sua esposa próximo a sua residência, os materiais estavam em um carrinho de bebe [...] (TELESPECTADOR, 2016).

Figura 2 - Informações de fonte confiável, mas não oficial.

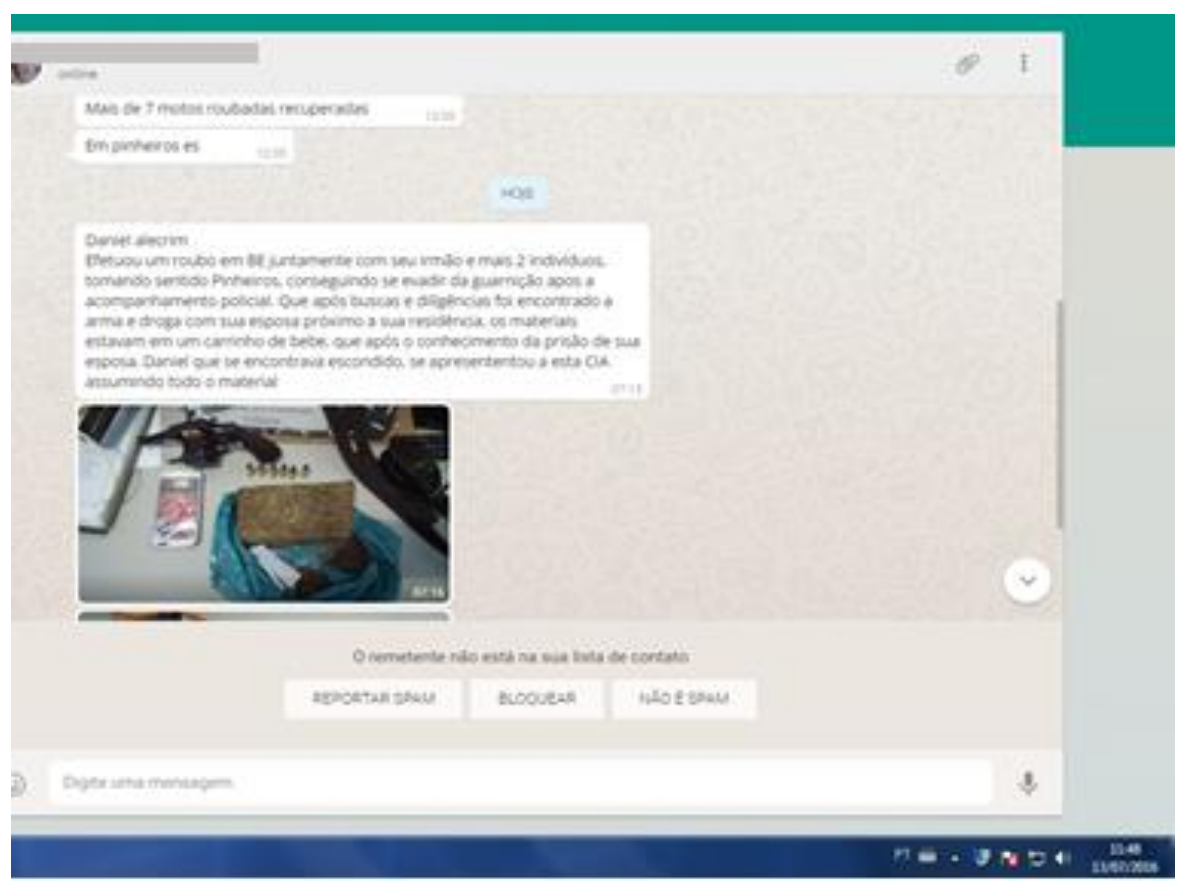

Fonte: captura de tela realizada pelos autores.

Inúmeras vezes o factual só foi exibido porque um dos "amigos do TN" estava atento, pronto para registrar e, sobretudo, disposto a compartilhar o registro do acontecimento. Tomemos como exemplo um acidente ocorrido no dia 13 de julho de 2016. Nenhuma equipe jornalística chegou a tempo de filmar a cena: um carro capotado no meio da pista; mas a nota coberta, com informações e imagens, foi ao ar no mesmo dia, no TN, graças a um dos telespectadores, que passava pelo local no momento do acidente e que, além de gravar as cenas, coletou informações não oficiais sobre o fato e até sobre as condições do motorista do veículo. Antes do material recebido, foi exibida a vinheta que reproduz o barulho típico do aplicativo quando anuncia a chegada de uma nova mensagem. O texto, escrito pelos editores e lido pelos apresentadores, apareceu em estilo coloquial e reforçava a importância da participação do receptor no processo noticioso, tanto na abertura da matéria quanto na nota-pé complementar. A equipe analisou que o fato era de interesse do público, separou as imagens exatamente como chegaram e exibiu sem edições. Depois da vinheta, os apresentadores afirmaram: “Vinhetinha rodou, amigo do TN apareceu. Ele narra um

\footnotetext{
7 Boa Esperança, município localizado no norte do Espírito Santo.
} 
acidente que aconteceu no bairro Lagoa de Jacaraípe, na Serra. O motorista bebeu, perdeu o controle do carro... e o veículo ficou desse jeito. Veja aí".

Depois da exibição do material, os apresentadores agradeceram e reforçaram o número do telefone para novas colaborações:

O nosso amigo que narrou o acidente preferiu não se identificar, mas contou que o motorista realmente bebeu... e saiu sem ferimentos. Deu sorte! Porque o que mais estamos vendo é mortes no trânsito de motoristas que insistem em beber e dirigir. Infelizmente é verdade. Bom, agradecemos o vídeo que o nosso amigo mandou pra gente mostrando essa imprudência absurda. Participe do TN também. $O$ número do nosso WhatsApp pra você mandar sugestões, flagrantes, curiosidades é o 99792-25- 30 (APRESENTADORES, 2016).

Na figura abaixo, é possível avaliar a paginação do telejornal, determinada, como todos os dias, pela editora-executiva. O material resultante do que foi enviado pelo telespectador (incluindo vinheta e nota) foi paginado ainda no primeiro bloco, em um momento em que a briga pela audiência com os dois

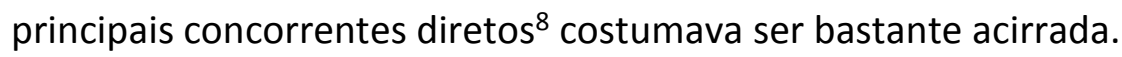

Figura 3 - Paginação (espelho do telejornal)

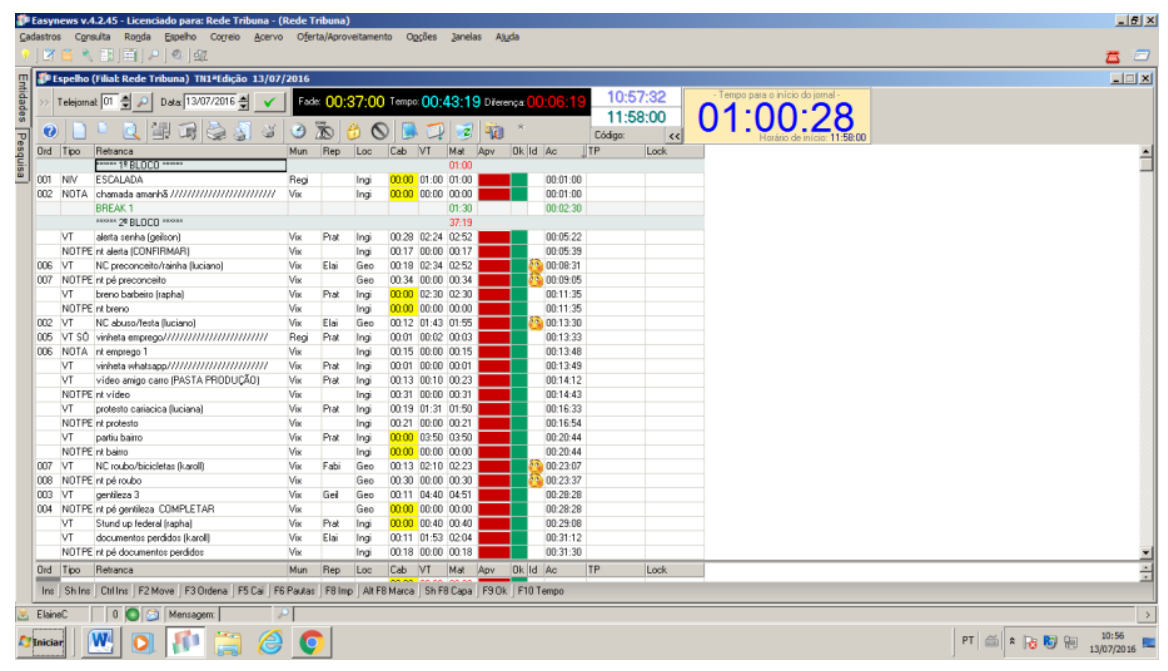

Fonte: captura de tela realizada pelos autores.

O envio espontâneo de mensagens compunha a grande maioria dos contatos, mas não era sempre assim. Por vezes, quando verificado que a pauta era interessante, mas não havia disponibilidade de equipes, a questão era resolvida diretamente pelo WhatsApp. As produtoras pediam aos telespectadores

\footnotetext{
${ }^{8}$ ES TV $1^{\text {a }}$ edição exibido pela TV Gazeta, afiliada da Rede Globo, e Balanço Geral, programa da TV Vitória, afiliada à Record TV. Em fevereiro de 2018, o telejornal Tribuna Notícias 1ạ edição ocupava o terceiro lugar em audiência, de acordo com a medição feita pelo Ibope. O Balanço Geral ES liderava, seguido do ES TV 1a edição.
} 
que registrassem o fato e enviassem pelo aplicativo. Não houve ocasião em que não tenham sido atendidas se as condições técnicas possibilitassem esse envio. Nos lugares onde as equipes também não estavam autorizadas ou enfrentavam burocracia para entrar, como hospitais, terminais de ônibus e shoppings, a boa vontade dos "amigos do TN" para registrar as imagens em seus dispositivos móveis era fundamental.

A maioria das mensagens chegava no período da manhã, com destaque para os minutos em que o jornal estava sendo exibido. Perguntada se acreditava haver maior identificação entre público e redação após o WhatsApp, uma das produtoras respondeu:

Sim, uma cobrança maior também. Quem utiliza, em sua maioria, são pessoas carentes, de tudo: atenção, carinho, saúde, favor, emprego. Eles brigam quando não vamos, elogiam nosso jornal, criticam e elogiam nossos apresentadores e elogiam nossos repórteres. Botam a boca no trombone quando damos uma informação incorreta (PRODUTORA 1, 2016).

Órgãos e instituições oficiais, como secretarias de Governo, ainda preferiam utilizar o e-mail para envio de releases com sugestões de pauta, apesar de muitos também estarem disponíveis para troca rápida de mensagens por meio do telefone celular. Nestes casos, geralmente o e-mail era enviado com solicitação de confirmação para facilitar o controle das sugestões ou respostas enviadas. Depois da oficialização da demanda, aí sim o contato às vezes passava para o WhatsApp ou a conversa continuava no espaço destinado ao bate-papo instantâneo nas caixas de e-mail.

Em dias com grandes acontecimentos como passeatas, querelas políticas, ou quando havia um crime de grande repercussão, o número de mensagens aumentava significativamente, como, por exemplo, quando houve dificuldade para tomar vacina contra gripe H1N1; filas para recadastramento biométrico em cartórios eleitorais; medo da dengue, zika e chikungunya; a visita do então deputado federal Jair Bolsonaro (PSC-RJ) ao Espírito Santo; as eleições municipais; o grave índice de desemprego enfrentando no período; as disputas entre os favoráveis ao impeachment da Presidenta Dilma Roussef e os que acreditavam que tudo não passava de um golpe. E, com bem menos relevância, mas não menos quantidade de mensagens, a barba do apresentador, que resolveu mudar o estilo, deixando que ela crescesse e fosse pintada de preto.

As mensagens eram, em sua grande maioria, enviadas por telespectadores da Grande Vitória, com pouquíssima participação de moradores de outros municípios do estado. Durante as seis semanas de 
análise, intercaladas em meses diferentes, foram apenas quatro ocorrências: uma denúncia política; um pedido para divulgação de festa; um pedido por melhorias em um bairro cheio de buracos; e, única que foi aproveitada pela equipe, a denúncia de uma agressão praticada por um político. Esta solicitação inclusive foi citada por uma das produtoras como um erro de avaliação pessoal: "Eu tomei um furo. Recebi o vídeo de um político batendo em um carro de som, apurei, salvei o vídeo, mas esqueci de avisar para os editores. No jornal da noite o vídeo estava na concorrência. Foi horrível!!!" (PRODUTORA 2, 2016).

A quantidade reduzida de material recebido de outras localidades pode ser explicada pela pequena penetração da programação local da TV Tribuna no interior. A qualidade do sinal que chega aos municípios mais distantes gera muitas reclamações, e muitos telespectadores optam por canais concorrentes ou por canais de TV por assinatura. As equipes da TV Tribuna raramente fazem reportagens fora da região metropolitana, por falta de equipe e recursos econômicos.

Boa parte das mensagens trazia informações ou denúncias relacionadas a criminalidade ou serviço, o que pode ser explicado pela característica de telejornalismo policial adotada por muitos anos e que ainda fazia parte da percepção que o público tinha do produto. As mensagens que traziam solicitações de demandas comunitárias também sempre eram registradas em bom número: falta de asfalto, de esgoto, mosquitos em excesso, falta de área de lazer, entre outras.

As solicitações foram tantas que inspiraram a criação de um quadro especial, o "Partiu, bairro!”, só para atendê-las. Feito de forma bem leve e descontraída, o quadro era comandado por um repórter único, o jornalista Felipe Chicarino, para fortalecer a identificação. Vestido com a camisa que informa o nome do quadro, e deixando bem clara a intenção do profissional, a orientação era realizar as reportagens com a participação dos moradores, de maneira bem entrosada, muitas vezes utilizando o humor como recurso para a denúncia.

Figura 4 - Telespectadora elogia o quadro "Partiu, bairro!". 


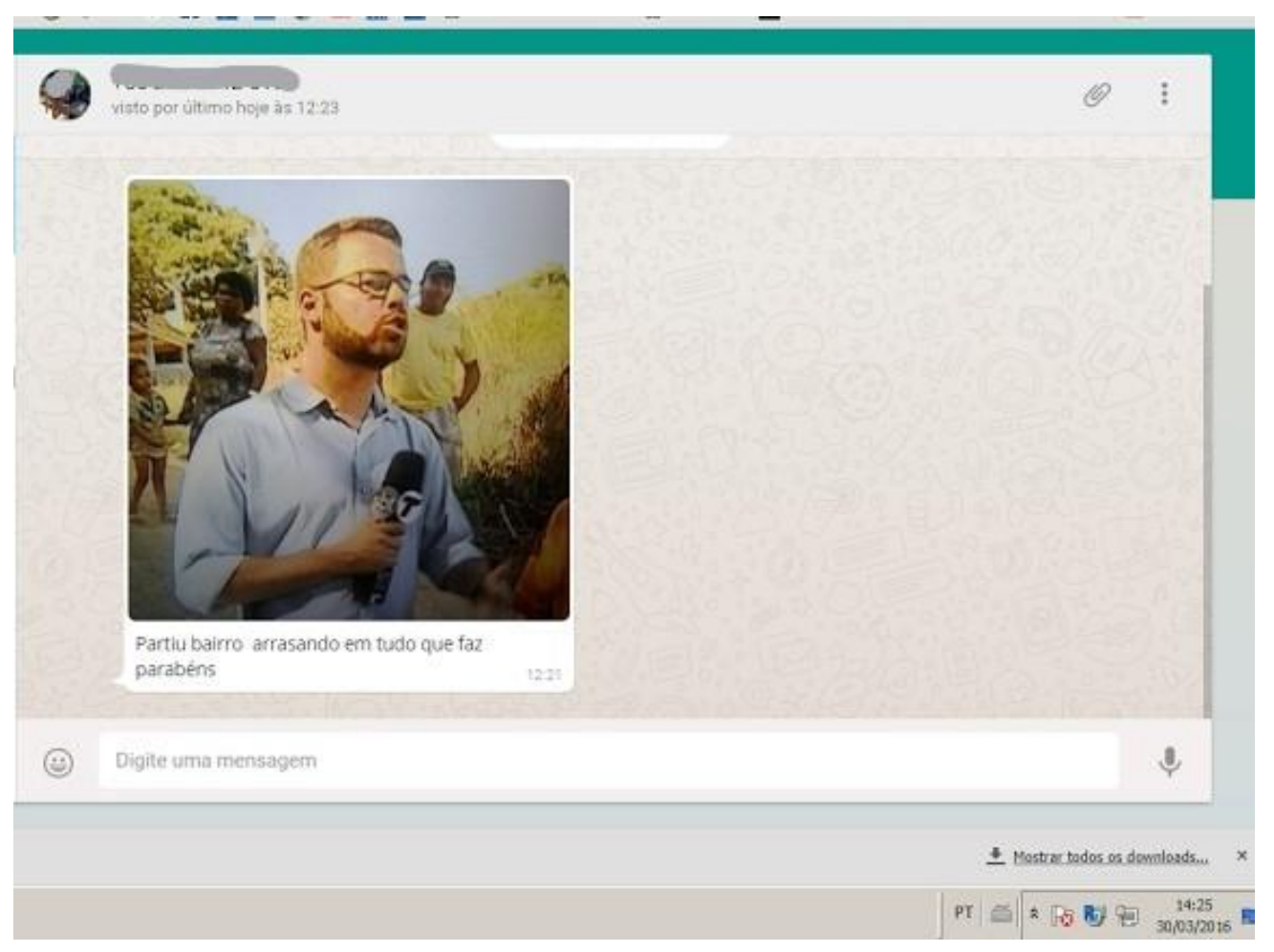

Fonte: captura de tela realizada pelos autores.

As reclamações deste tipo, que chegavam por meio do aplicativo, eram sempre anotadas e, em boa parte das vezes, atendidas, apesar de serem bem parecidas entre si, variando apenas de comunidade. São elas que abasteciam a produção de pautas para o quadro e reforçavam a parceria com os "amigos do TN". De certa forma, o incentivo à participação neste caso acaba por se retroalimentar. Quando o "Partiu, bairro!" entrava no ar, o número de mensagens recebidas por meio do aplicativo aumentava consideravelmente. No dia 20 de julho de 2016, por exemplo, das 11 mensagens que traziam solicitações de comunidades, nove chegaram enquanto o quadro era exibido ou imediatamente após a exibição. A análise das outras mensagens do dia 20 estará detalhada mais à frente.

É como se fosse um lembrete para o telespectador de que ele tem uma demanda para enviar, de que ele tem um canal de reivindicação. Musse e Thomé $(2015$, p. 5), ao analisarem as reclamações e denúncias enviadas pela audiência às TVs, afirmam que os telespectadores "[...] entregam ao telejornal a função de defensor e de mediador na sua relação com o poder público, legitimando o poder da imprensa". 


\section{Volume, natureza e aproveitamento das mensagens enviadas por telespectadores}

Com o objetivo de quantificar e avaliar a natureza das mensagens e a importância desses conteúdos para o resultado final da edição do telejornal, vamos detalhar agora algumas das edições presentes na nossa amostra de seis semanas. Os dias explicitados a seguir foram escolhidos por serem significativos para exemplificar um padrão que se repetiu durante as seis semanas de monitoramento.

No dia 14 de outubro de 2015, uma quarta-feira, da 00 h03 (momento do primeiro contato) até às $12 \mathrm{~h} 39$ (horário do término do TN), foram enviadas ao WhatsApp 395 mensagens, e em, pelo menos, 150 delas havia sugestões de pauta. O restante era formado por elogios, reclamações, solicitações de beijo ou divulgação de fotos, vídeos retirados da internet, pedidos de emprego e dinheiro, mensagens religiosas ou de motivação, cantadas, além das mensagens de "bom dia" (18), de apenas "oi" (29), e das que eram um retorno de contatos anteriores já respondidos pela equipe (53). Do material total recebido, duas mensagens viraram notas cobertas no telejornal: o vídeo que mostrava um passageiro abusando de uma estudante e as fotos de uma senhora de 93 anos que conseguiu se encontrar com a atriz mirim Maísa. Para outras três sugestões, foram marcadas reportagens imediatamente: professores assaltados, falta de iluminação perto de uma escola, vizinhos incomodados com o barulho de galos. Pelo menos outras 20 foram cadastradas para análise por parte da chefe de reportagem.

Gráfico 1 - Aproveitamento de mensagens no dia 14/10/2015.

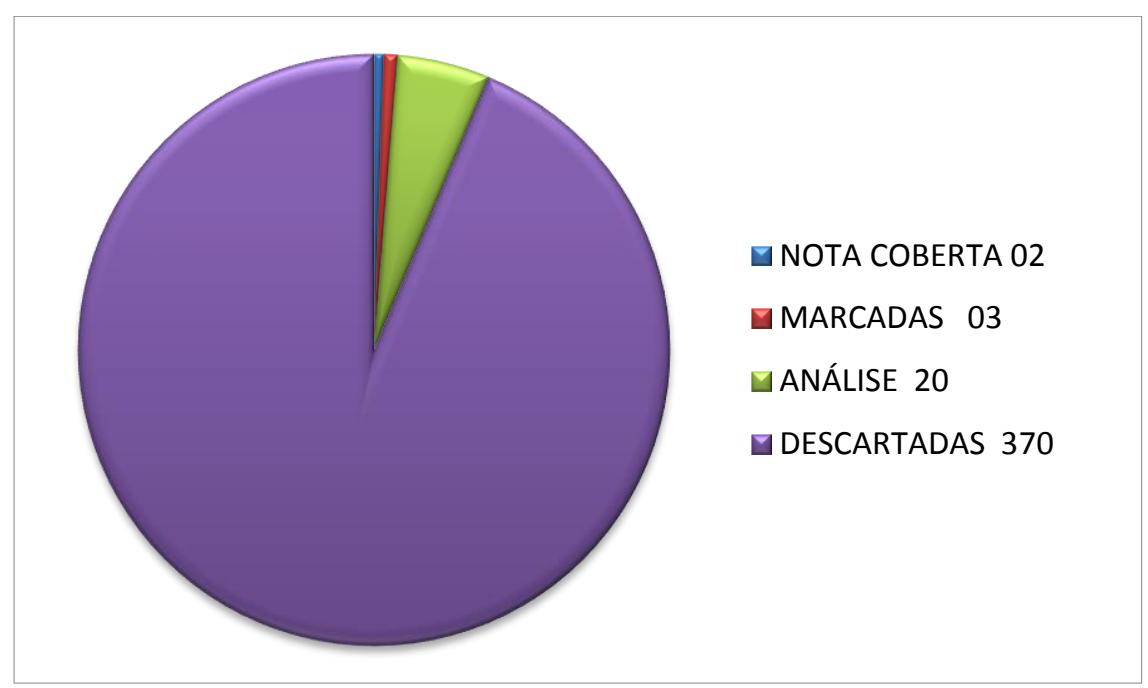

Fonte: levantamento realizado pelos autores 
No dia 30 de março de 2016, uma quarta-feira, foi recebido um total de 182 mensagens. A primeira foi enviada às $01 \mathrm{~h} 18$ (vídeo de um político sendo agredido com uma torta no rosto) e a última foi registrada às $12 \mathrm{~h} 41$. Apenas 30 receberam alguma resposta por parte da produção. O TN foi adicionado a seis grupos de mensagens, todos apagados. Uma pessoa foi bloqueada por enviar pornografia. A reportagem que mais gerou comentários foi sobre a morte do rapaz dentro do supermercado, exemplo que abre este artigo. Apenas uma mensagem foi aproveitada pelo telejornal: um vídeo de moradores linchando um suposto bandido, arquivo enviado por três telespectadores diferentes. Quatro sugestões recebidas viraram pauta: uma criança que caiu em um bueiro e três reclamações de problemas em bairros.

Gráfico 2 - As mensagens ignoradas somaram 81\% no dia 30/03/2016.

\section{TOTAL DE MENSAGENS: 182}

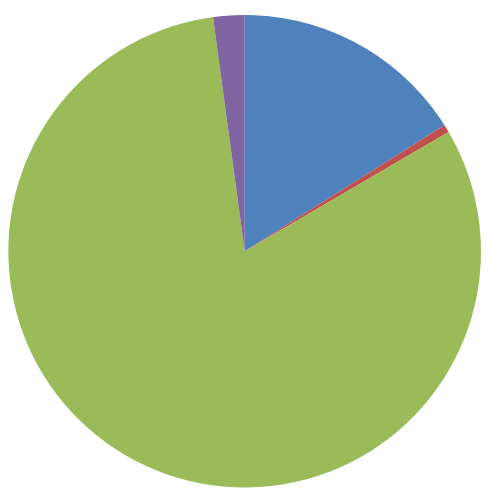

RESPONDIDAS: 30

APROVEITADAS: 01

IGNORADAS: 152

PAUTAS: 04

Fonte: levantamento realizado pelos autores

Podemos verificar que $81 \%$ das mensagens recebidas no dia ficaram sem qualquer tipo de resposta. A porcentagem alta pode ser creditada em parte ao caso do ladrão de picanha. As duas produtoras foram muito demandadas no dia, buscando as confirmações para os dados novos que chegavam sobre o caso, remarcando pautas que caíram por causa do factual, e correndo atrás dos posicionamentos da polícia, da família da vítima e dos responsáveis pelo supermercado. Apesar de tanto trabalho, a determinação era que a análise do WhatsApp não fosse interrompida; por isso, esse é um caso que ilustra bem os impactos que o uso do aplicativo representou para a rotina na redação.

Apresentamos agora o detalhamento da edição de sexta-feira, dia primeiro de abril de 2016. A data marcou a visita do então deputado federal Jair Bolsonaro ao Espírito Santo. Nenhum material recebido por 
meio do aplicativo foi aproveitado por falta de tempo disponível no telejornal. Apesar disso, verificamos o envio de 181 mensagens durante o período de produção e exibição do jornal. O TN foi adicionado a cinco grupos. As mensagens de contato como "oi", "beijo", "bom dia”, religiosas, vídeos de internet ou correntes somaram 35. Trinta e oito pessoas solicitaram reportagens em comunidade, como ônibus atrasado, esgoto, asfalto, etc. Foram recebidas 23 sugestões de matérias policiais, como assalto, denúncias, falta de segurança. Dez telespectadores solicitavam reportagens na área da saúde, como problemas de atendimento, filas em postos, vacinação. Três mensagens denunciavam questões ligadas à educação, como escolas em condições ruins, falta de uniforme. Quatro telespectadores enviaram opiniões sobre Bolsonaro ou fotos de sua chegada ao aeroporto. Foram registrados seis elogios ao telejornal ou apresentadores; oito retornos de contatos anteriores; três mensagens relacionadas a direitos do consumidor; dez mensagens com opinião em tempo real sobre reportagem exibida no telejornal (Bolsonaro, policial bate em mulher, dificuldade para vacinar). Cinco telespectadores cobravam respostas da redação do TN; oito informavam sobre trânsito e acidentes. Três mensagens continham apenas arquivo de áudio e não foram ouvidas pela produção; e 25 foram classificadas como sendo de outra natureza: pedido de emprego, doações, boatos, manifestação, fumaça provocada por incêndio em turfa, propaganda, desaparecidos, pornografia, entre outros.

Gráfico 3 - A natureza das mensagens no dia 01/04/2016.

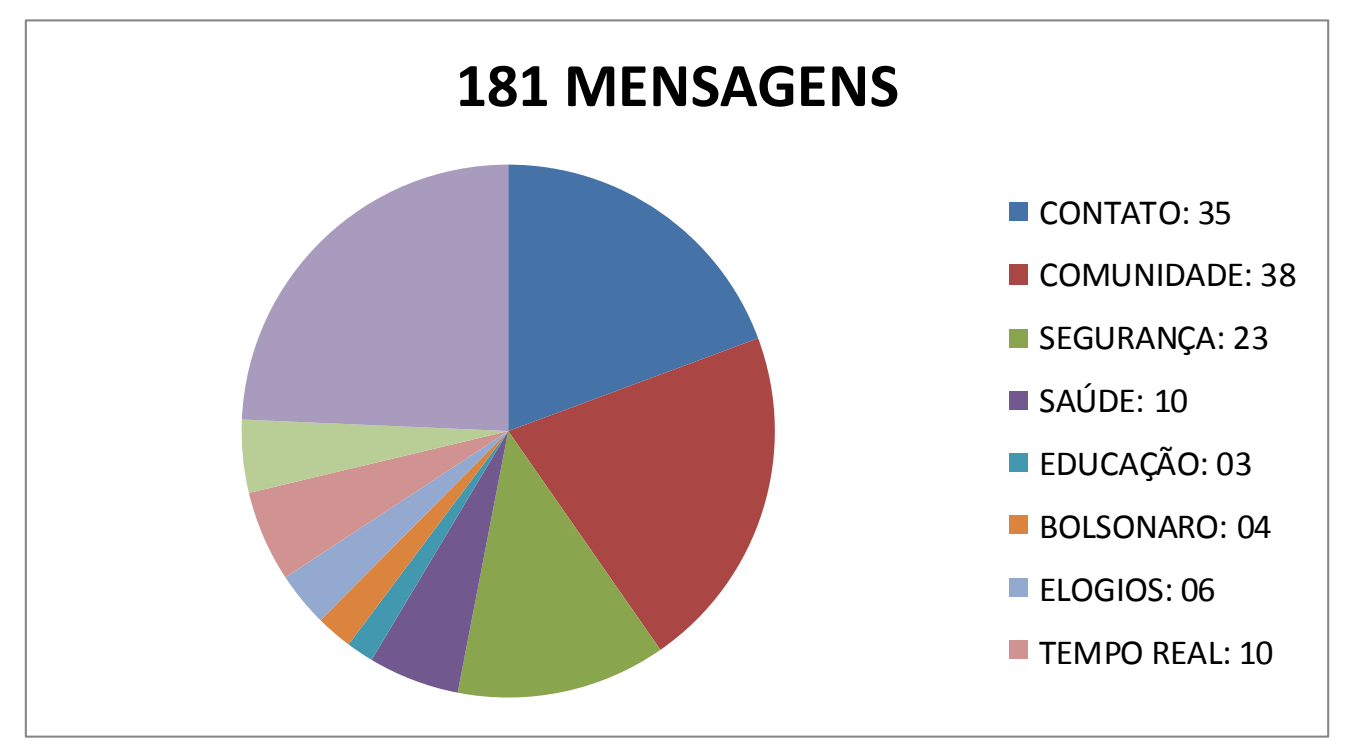

Fonte: levantamento realizado pelos autores 
No dia 20 de julho de 2016, quarta-feira, o TN entrou no ar ao meio-dia e saiu às $12 \mathrm{~h} 47$, e não houve caso de grande repercussão nem fator externo ou interno que demandassem os profissionais além do usual. A paginação feita pela editora-chefe foi padrão, com matérias policiais nos primeiros minutos, seguidas por reportagens de serviço. No último bloco, apenas vagas de emprego, como costuma acontecer quando o tempo do jornal excede o planejado, na maioria das vezes por causa dos comentários improvisados dos apresentadores.

Foi enviado um total de 140 mensagens. A primeira foi registrada às 06 h08 (link para um clip de música no Facebook). As mensagens recebidas até o TN começar somaram 68 (em 5 horas e 52 minutos). Durante a exibição do telejornal (47 minutos), foram enviadas 72 mensagens, isto é, mais da metade das enviadas em todo o período. Nove mensagens continham imagens compartilhadas da Internet (incluindo bichinhos, "bom dia" e crianças), e quatro eram vídeos também retirados da rede sobre animais, reportagem da emissora concorrente, pornográfico, sobre outro estado. Duas mensagens pediam a confirmação do número da TV no aplicativo. Seis mensagens de cunho religioso foram recebidas, quinze eram elogios, enquanto outras quinze traziam apenas um "bom dia" ou "boa tarde". Uma mensagem trazia um pedido de casamento para uma das repórteres.

O destaque do dia foram as dez mensagens com um flagrante de trânsito. Um carro da Polícia Rodoviária Federal que transitava com o farol apagado em via federal, logo após a lei que obriga o uso entrar em vigor, além das 11 mensagens com solicitações para o quadro "Partiu, bairro!" (nove delas enviadas durante ou imediatamente depois da exibição do quadro).

Podemos afirmar que as reclamações sobre problema de infraestrutura são maiores quando há exibição do quadro que mostra as demandas da comunidade. O número de mensagens também aumenta imediatamente após a divulgação do número de telefone pelos apresentadores. Em todo o período de análise, a quantidade de mensagens consideradas descartáveis pela equipe, ou seja, sem qualquer interesse jornalístico, é sempre muito maior do que as que são classificadas como úteis. 


\section{Considerações finais}

Diante dos resultados encontrados, podemos afirmar que a expectativa despretensiosa da redação do TN1, frente à iniciativa que buscava aumentar o número de pautas e a interação com o telespectador, deu lugar à surpresa pela grandiosidade dos números iniciais de resposta e engajamento do público. E foi seguida pelo despreparo na maneira de lidar com isso, fato que acabou gerando indignação por parte dos telespectadores.

O número de contribuições enviadas pela audiência vem caindo mês após mês, exceto quando há uma iniciativa pontual que provoque uma excitação temporária no telespectador. $\mathrm{O}$ fato é que, ao se doar, ao entregar o trabalho amador e não se ver representado, ao mandar mensagens que não são exibidas, ao sugerir e não ver a sugestão virando pauta, o "amigo do TN", cheio da intimidade que lhe foi atribuída, fica chateado e ressentido, algumas vezes reclamando, em outras migrando para a concorrência.

É importante destacar, entretanto, que esse descontentamento por parte dos telespectadores que participam do processo de produção enviando mensagens por meio do WhatsApp não parece significar, pelo menos no curto prazo, uma ameaça real à audiência, à credibilidade ou à formação de identidade do Tribuna Notícias, já que o volume real de participação ainda é pouco representativo. Se analisarmos os números do Ibope de 2016, veremos que o telejornal contava com uma média diária de 119.864 telespectadores. Levando-se em consideração a média de 300 mensagens diárias recebidas por meio do aplicativo no primeiro ano de utilização na redação, chegamos ao índice aproximado de 0,25\% do público total do TN. Ou seja, os outros 99,75\% dos telespectadores não produziram de maneira espontânea nem responderam aos apelos feitos para envio de material colaborativo no período da pesquisa. Não foram, portanto, impactados diretamente pelo retorno obtido ou pela falta dele.

Em relação à participação efetiva do público, acreditamos que ela ainda esteja marcada pela hierarquização nos processos de comunicação e, uma vez que o telespectador não participa da seleção do que será exibido, nem controla o enfoque que será dado ao material que enviou, ainda pode ser encarado como coadjuvante no processo de produção do telejornal. Após a realização da pesquisa, podemos afirmar que o "amigo do TN" não tem participação direta, muito menos participação ativa. Ele tem a chance de produzir conteúdo, mas não de escolher ou definir o que acontecerá depois que o material é cedido. 
Rafael da Silva Paes Henriques

ORCID: https://orcid.org/0000-0002-1812-5886

UFES, Programa de Pós-graduação em Comunicação e Territorialidades, Vitória (ES), Brasil.

Doutor em Filosofia pela UFRJ

E-mail:rafaelpaesh@gmail.com

Elaine de Lima Castro Garau

UFES, Programa de Pós-graduação em Comunicação e Territorialidades, Vitória (ES), Brasil. Mestra em Comunicação e Territorialidades pela UFES

E-mail: limacastroelaine@gmail.com

Recebido em: 14 de setembro de 2020.

Aprovado em: 11 de outubro de 2020.

\section{Referências:}

BECKER, B. Televisão e Telejornalismo: Transições. São Paulo: Estação da Letras e Cores, 2016.

CRARY, Jonathan. 24/7: capitalismo tardio e os fins do sono. São Paulo: Cosac Naify, 2014.

HAESBAERT, R. O mito da desterritorialização: Do fim dos territórios à multiterritorialidade. Rio de Janeiro: Bertrand Brasil, 2011.

MARTINS, M. O. Reconfigurações no telejornalismo a partir da popularização das câmaras amadoras: sobre a narrativa em primeira pessoa. In: XXXVII Congresso Brasileiro de Ciências da Comunicação, Foz do Iguaçu, $\quad$ PR, 2014. Anais eletrônicos. Disponível em http://www.intercom.org.br/papers/nacionais/2014/resumos/R9-0763-1.pdf.

MUSSE, C.F.; THOMÉ, C. Um milhão de amigos no RJTV: o telespectador como produtor de conteúdo pelos aplicativos WhatsApp e Viber. Sessões do Imaginário, v.20, n. 33, p. 01 - 09, Porto Alegre: 2015. 


\section{Resumo}

O objetivo deste artigo é descrever e avaliar como a utilização do WhatsApp afetou o relacionamento entre jornalistas e público, e alterou as rotinas produtivas na redação do telejornal Tribuna Notícias 1ạ edição, nos 18 primeiros meses de implantação, entre abril de 2015 e outubro de 2016. Para cumprir com essa tarefa, este estudo de caso utilizou a revisão bibliográfica, a observação participante e a entrevista semiestruturada. O telejornal foi analisado durante seis semanas não consecutivas, em meses diferentes, sempre fazendo o acompanhamento semanal de quarta a quarta. Como resultados encontrados, podemos apontar que apesar de a participação do telespectador ser muito incentivada durante o telejornal e o clima de intimidade reforçado a cada fala, o telespectador não tem conhecimento das necessidades do processo jornalístico ou dos interesses da empresa e, por isso, ainda se mantém distante da seleção do que será efetivamente exibido.

Palavras-chave: Telejornalismo. Rotinas Produtivas. Interatividade. Tribuna Notícias 1a edição. WhatsApp.

\section{Abstract}

This article aims to evaluate how the use of the WhatsApp application affected the relationship between journalists and the audience, and changed the productive routines in the newsroom of the Tribuna Notícias lunch time news show in the first 18 months of its implementation (between April 2015 and October 2016). In order to accomplish this task, this case study employs bibliographic review, participant observation and semi-structured interviews. The newscast was analyzed for six non-consecutive weeks, in different months, always from Wednesday to Wednesday. Our findings demonstrate that the viewers are not aware of the needs of the journalistic practice neither of the company's interests, and do not affect the selection of topics that will be covered by the show in a meaningful way.

Keywords: News Report. Productive Routines. Interactivity. Tribuna Notícias. WhatsApp. 


\section{Resumen}

El propósito de este artículo es describir y evaluar cómo el uso de WhatsApp afectó la relación entre periodistas y el público, y cambió las rutinas productivas en la sala de redacción del programa de noticias Tribuna Notícias 1a edición, en los primeros 18 meses de implementación, entre abril de 2015 y octubre de 2016 Para cumplir con esta tarea, este estudio de caso utilizó la revisión bibliográfica, la observación participante y la entrevista semiestructurada. El noticiero se analizó durante seis semanas no consecutivas, en diferentes meses, siempre monitoreando semanalmente de miércoles a miércoles. Según los resultados encontrados, podemos señalar que aunque la participación del espectador es altamente alentada durante el noticiero y la atmósfera de intimidad reforzada con cada discurso, el espectador no es consciente de las necesidades del proceso periodístico o los intereses de la empresa y, por lo tanto, todavía se mantiene alejado de seleccionar lo que realmente se mostrará.

Palabras clave: Teleperiodismo. Rutinas Productivas. Interactividad. Tribuna Notícias 1ạ edición. Whatsapp.

Este artigo é publicado em acesso aberto (Open Access) sob a licença Creative Commons Attribution Non-Commercial (CC-BY-NC 4.0), que permite que outros remixem, adaptem e criem a partir do seu trabalho para fins não comerciais, e embora os novos trabalhos tenham de lhe atribuir o devido crédito e não possam ser usados para fins comerciais, os usuários não têm de licenciar esses trabalhos derivados sob os mesmos termos. 